\title{
A INSUFICIÊNCIA DA EMANCIPAÇÃO POLÍTICA NA BUSCA PELA LIBERDADE REAL DO HOMEM NO JOVEM KARL MARX
}

\author{
THE INSUFFICIENCY OF THE POLITICAL EMANCIPATION IN THE SEARCH \\ FOR REAL HUMAN LIBERATION IN THE YOUNG KARL MARX
}

\author{
Bruno Fernandes ${ }^{1}$ \\ (brunofernandesfh@gmail.com)
}

Monica Loyola Stival ${ }^{2}$

Orientadora

\begin{abstract}
RESUMO
Karl Marx (1818-1883) escreve o ensaio Sobre a questão judaica (1843) para se contrapor à solução proposta por Bruno Bauer (1809-1882) acerca da relação entre o Estado prussiano e as reivindicações de emancipação do povo judeu alemão. Para Marx, a emancipação política, objetivo de Bauer, é insuficiente para a libertação do homem como sujeito não alienado; para tal, o que se deve reivindicar é a emancipação humana. A partir disso, nosso artigo discute as distinções e limites fundamentais entre a emancipação política e a humana. Neste sentido, pretendemos desenvolver a tese de que a emancipação política é insuficiente para superar as contradições em que vive o homem. Ao contrário do que pensa Bauer e os judeus, ao reivindicar um Estado democrático-burguês, a superação positiva e irrefutável da religião não está pressuposta.
\end{abstract}

Palavras-chave: Emancipação Política. Emancipação Humana. Jovem Marx.

\begin{abstract}
Karl Marx (1818-1883) writes the essay On the Jewish Question in order to raise against the solution proposed by Bruno Bauer (1809-1882) concerning the relation between the Prussian state and the emancipation demands of the German Jewish people. According to Marx, the political emancipation, which is Bauer's purpose, is insufficient for the human's liberation as a real individual, rid of alienation; To this end, what must be claimed is the human emancipation. Based on that, our article discusses the fundamental distinctions and limits between the political and human emancipation. Following these discussions, we intend to develop the thesis on the insufficiency of political emancipation when it comes to overcome of the contradictions in which humans live. Contrarily to what Bauer and the Jewish think, by claiming a democratic-bourgeois, one must not expect to overcome religion positively and undeniably.
\end{abstract}

Key Words: Political Emancipation. Human Emancipation. Young Marx.

\footnotetext{
${ }^{1}$ Graduando em Filosofia pela Universidade Federal de São Carlos (UFSCAR). Bolsista FAPESP. CV Lattes: http://lattes.cnpq.br/3177381415438148.

${ }^{2}$ Professora Dr. ${ }^{a}$ do Departamento de Filosofia da Universidade Federal de São Carlos (UFSCAR) CV Lattes: http://lattes.cnpq.br/0624149613819754.
} 


\section{INTRODUÇÃ̃O}

Entre 1789 e 1791 a Assembleia Constituinte francesa buscou, a partir do que Friedrich Engels chamou de "tribunal da razão" em o Anti-Dühring (1878), substituir "o mundo que, até então, havia estado envolto em trevas", marcado por injustiça, privilégio e opressão, por um mundo novo, marcado pela "verdade eterna, pela justiça eterna, pela igualdade baseada na natureza e por todos os direitos inalienáveis do homem" (ENGELS, 1979, p.17). É neste registro que a Assembleia também buscou superar toda discriminação legal contra o povo judeu, concedendo-lhes igualdade de direitos em relação aos demais cidadãos. Segundo Eric Hobsbawm, “A maioria dos empreendimentos institucionais duradouros da revolução datam deste período, assim como os seus mais extraordinários resultados internacionais, o sistema métrico e a emancipação pioneira dos judeus" (HOBSBAWM, 1977, p. 82, grifo nosso).

A dupla revolução - "a francesa, bem mais política, e a industrial (inglesa)" “proporcionou aos judeus a sensação mais próxima à igualdade que eles jamais tinham gozado em uma sociedade cristã" (HOBSBAWM, 1977, p.218). Com esses avanços, em alguma medida, os judeus renanos também foram beneficiados, pois durante o império napoleônico parte da Alemanha era administrada pela França e, portanto, submetida às suas deliberações. Porém, após o Tratado de Viena, a Santa Aliança (uma coligação criada pelas potências monárquicas da Europa contra os levantes da Revolução Francesa) se vale da queda de Napoleão na Bélgica (1815) e retoma o controle do território, restabelecendo a noção de Estado cristão. A partir disso, um edito de quatro de maio de 1816 proíbe efetivamente aos judeus da Alemanha o acesso às funções públicas. Manifestações contra o povo judeu ascenderam em 1819, na Baviera; mais tarde, outras perseguições foram alimentadas pelas acusações de assassinato ritual, lançadas em 1840, em Damasco (BENSAÏD, 2009, p.19). O debate sobre os direitos cívicos dos judeus tornou-se uma reivindicação liberal, chegando a um ponto culminante na Alemanha. Por um lado, o povo judeu alemão almeja a emancipação cidadã (Die staatsbürgerliche Emanzipation), a emancipação política (Die politische Emanzipation), por outro, o Estado prussiano assume seu caráter cristão, negando a eles igualdade em relação aos demais; suprimindo condições humanas universais por conta do seu preconceito religioso. $\mathrm{Na}$ época, muitos se posicionaram sobre o assunto, inclusive Bruno Bauer e Karl Marx. 
Podemos resumir as conclusões de Bruno Bauer acerca da relação entre o Estado prussiano e as reivindicações de emancipação do povo judeu alemão, com o seguinte trecho:

O Estado cristão, por sua própria essência, não pode emancipar o judeu; o judeu, por sua própria essência não pode ser emancipado. Enquanto o Estado for cristão e o judeu judaico, ambos serão igualmente incapazes tanto de conceder quanto de receber a emancipação. (MARX, 2010, p.34)

Essa conclusão é alcançada após uma série de argumentos que indicam, assim como o parágrafo retomado, que Bauer compreende o problema como um antagonismo religioso, conduzindo-o ao campo teológico; considerando as condições segundo as quais um Estado revestido de uma religião particular deve tratar da liberdade e igualdade reivindicada para cidadãos vinculados a outra religião particular, religião esta que, nas palavras de Bauer, "é inimiga mortal da religião do Estado" (MARX, 2010, p.34). O antagonismo entre judeu e cristão é solucionado a partir da superação da religião, e isso para o homem deixar de se encontrar em uma relação religiosa e passar a se encontrar em uma relação "crítica, científica e humana" (MARX, 2010, p.34).

Para Bauer: "Não havendo religião privilegiada não há mais nenhuma religião. Tirai da religião seu poder de excluir e ela deixará de existir" (MARX, 2010, p.34). Essa solução tem como fim o ateísmo, pois a condição posta para a emancipação cidadã para o judeu seria a renúncia ao judaísmo, e assim serve para o Estado chamado cristão que quer emancipar e ser ele próprio emancipado. De acordo com Bauer, o Estado que pressupõe a religião ainda não é um Estado real, pois age de forma excludente para com as demais religiões. Sua análise tem como objetivo a superação política de toda religião em prol da construção de um Estado não religioso, de um Estado democrático-burguês. Essa afirmação fica evidente quando Bauer busca superar a oposição entre a religião judaica e o cidadão superando, antes, a religião. Para ele, a questão judaica estaria resolvida na França (que era um Estado constitucional), por exemplo, quando as leis judaicas não mais impedissem o judeu de cumprir deveres para com o Estado. Assim, o judeu já teria deixado de ser judeu. Desta forma, ele sugere que "esse cumprimento deveria ser deixado por conta deles como questão puramente privada” (MARX, 2010, p.36), para que assim se dissolva qualquer privilégio religioso, qualquer monopólio de uma igreja privilegiada. Segundo Bauer,

A liberdade ainda não é lei na França, e a questão judaica ainda não foi resolvida, porque a liberdade jurídica - de que os cidadãos 
são iguais - é restringida na vida real, a qual é dominada e fragmentada pelos privilégios religiosos, e essa falta de liberdade da vida retroage sobre a lei, forçando-a a sancionar a diferenciação dos cidadãos em si livres em oprimidos e opressores. (MARX, 2010, p.35)

Com isso, ao apontar a insuficiência do direito na prática, Bauer nos dá indícios de compreender os limites da emancipação política. Porém, se contradiz quando pergunta aos judeus se "Tendes, a partir do vosso ponto de vista, o direito de almejar a emancipação política?” (MARX, 2010, p.36). Como várias questões feitas por Bauer, essa não é uma questão fundada na essência da emancipação política mesma. Marx acompanha esses argumentos e inicia sua crítica, perguntando se "O ponto de vista da emancipação política tem o direito de exigir dos judeus a supressão do judaísmo e do homem de modo geral a supressão da religião?" (MARX, 2010, p.37). Bauer não compreendeu bem o que ele próprio reivindicava, fez questões equivocadas e, com isso, chegou apenas aos limites da crítica à teologia. A questão judaica formulada nessas condições, isto é, uma oposição irreconciliável entre o Estado chamado cristão e o envolvimento religioso, limita-se a uma crítica de dois gumes, crítica à teologia cristã e à teologia judaica, movendo-se ainda no interior da teologia.

Considerando a solução nos termos de Bauer, ou seja, o judeu deve abandonar o judaísmo - e o homem em geral a religião - para ser emancipado como cidadão, cabe destacar que o objetivo de Marx é expor aos demais filósofos (e a Bauer) que eles deviam sair dos limites de uma crítica ao chamado Estado cristão e passar à crítica do Estado desenvolvido, pois: "Só onde o Estado político existe em sua forma plenamente desenvolvida, a relação do judeu, de modo geral, do homem religioso, com o Estado político, ou seja, a relação entre a religião e o Estado, pode emergir em sua peculiaridade, em sua pureza" (MARX, 2010, p.37).

Todavia, "como se comporta, então, a emancipação política plena para com a religião?" (MARX, 2010, p.38). Citando como exemplo a América do Norte, uma realidade diferente da alemã, Marx evidencia que alguns estados americanos são livres de qualquer vínculo religioso, eles agem politicamente para com a religião. No país da religiosidade, que considera um homem sem religião até mesmo desonesto, as cadeias religiosas permanecem vivas e atuantes. Com isso, Marx nos mostra, primeiro, que a existência da religião nos estados livres norteamericanos atesta que não há oposição entre Estado e religião quando o primeiro é secular (weltliche), isto é, a religião não contradiz a plenificação do Estado; depois, que a emancipação política não deve ser confundida com a emancipação humana (Die menschliche Emanzipation).

Essa confusão é justificada pelo chamado "atraso alemão" em relação à França, Inglaterra e Estados Unidos. O historiador francês, François Furet, em Marx 
e a Revolução Francesa (1986), apresenta duas ideias centrais para compreender o trabalho intelectual do jovem Marx sobre a Revolução Francesa, sendo uma delas justamente a sua obsessão com o atraso alemão. (A segunda ideia central apresentada no texto de Furet destaca um "desdobramento crítico" que situa Marx "no campo da crítica feuerbachiana de Hegel”, crítica que "preside à elaboração de um novo conceito de Estado", e que tem papel essencial na “desmistificação” empregada por Marx na Crítica de 1843 (FURET, 1986, p.8)). Segundo ele, "Marx compartilha a paixão de todos os intelectuais alemães por resgatar a história de seu país, cuja quase inexistência acentua-se pelo brilho constante e universal da Revolução Francesa" (FURET, 1986, p.8-9). Para Marx, a Alemanha do século XIX manteve a consagração franca e sincera do ancien régime, comportando-se como o "suprassumo do mundo filisteu", mundo onde "os homens adicionavam-se à propriedade dos seus senhores como uma criação de escravos ou de cavalos", sem conhecer "outra destinação que a de serem submissos, amáveis e prestativos" (MARX, 2010, p.65). Diferentemente das nações modernas, onde o ancien régime experimentou sua tragédia (a França é o maior exemplo), na Alemanha ele "desempenha uma comédia" (MARX, 2010, p.148). Nesta situação, "a filosofia alemã do direito e do Estado seria a única história alemã que se encontra 'a pari' da atualidade moderna oficial”, pois na esfera da prática, “está abaixo do nível da história, está abaixo de toda crítica” (MARX, 2005, p.150).

É com esse tom que Marx nos mostra, na Crítica da filosofia do direito de Hegel Introdução (1843), que o Estado mais atrasado pode ser o Estado mais adiantado. Sua intenção é anunciar a possibilidade de uma revolução na Alemanha justamente por conta do seu atraso, isto é, por não vivenciar a emancipação política na prática, pois os alemães tomaram "parte nas restaurações das nações modernas, sem ter tomado parte nas suas revoluções” (MARX, 2005, p.150), seria possível conhecer seus limites, e a partir da crítica do Estado político pleno, como o americano, caminhar em direção à revolução alemã de modo consciente. Esse projeto, segundo Furet, "desempenharia a função histórica de ultrapassar a emancipação francesa, superando seus limites: daí a exigência intelectual de elaborar inicialmente uma filosofia crítica da Revolução Francesa" (FURET, F. 1986, p.8). Essa importância dada ao feito francês é justificada por Eric Hobsbawn. Para ele, a Revolução Francesa é a mais importante das revoluções contemporâneas, por ter sido a única ecumênica.

A França forneceu o vocabulário e os temas da política liberal e radicaldemocrática para a maior parte do mundo. A França deu o primeiro grande exemplo, o conceito e o vocabulário do nacionalismo. Ela forneceu os códigos legais, o modelo de organização técnica e científica e o sistema métrico de medidas para a maioria dos países. (HOBSBAWN, 1996, p.11) 
Apesar disso, como veremos mais tarde, a emancipação política empreendida pelos franceses é parcial e insuficiente. O proletariado entra em cena pela primeira vez, como condição da possibilidade positiva da emancipação alemã, emancipação que seria resultado de uma revolução não mais apenas política, mas social. A intenção de Marx era a de conduzir a práxis alemã ao nível de sua filosofia. Entretanto, por "viver sua pós-história em pensamento" (MARX, 2010, p.150), a emancipação política e a humana puderam ser confundidas e percebidas mais nitidamente na Alemanha. Na concepção de Bauer, então, trata-se o problema admitindo apenas a relação entre emancipação política - acreditando ser ela a responsável pela verdadeira liberdade dos homens - e religião, acreditando que sua superação é necessária para reivindicar um Estado democrático-burguês. Nesse sentido, Marx trabalha em duas frentes: por um lado, ele busca tornar o atraso alemão do conhecimento de todos; por outro, aponta seu arsenal crítico na direção dos americanos e franceses, com o intuito de denunciar a insuficiência da emancipação conquistada por eles.

A partir da análise da situação americana, a crítica que antes era direcionada ao Estado chamado cristão, crítica teológica, transforma-se em crítica direcionada a toda forma de Estado, ao Estado político, crítica ideológica. Assim, Marx avança no que permanecia meramente no campo religioso. Ora, "a questão deixa de ser uma crítica teológica no momento em que o Estado deixa de comportar-se teologicamente para com a religião" (MARX, 2010, p.38).

Segundo Daniel Bensaïd, em uma carta enviada a Arnold Ruge, Marx “já indicava que a posição de Bauer lhe parecia 'extremamente abstrata', e muitíssimo pouco crítica em relação ao "Estado cristão" (MARX, 2010, p.24). A questão devia ser abordada por "outro ângulo", e Ludwig Feuerbach era a chave dessa abordagem: ele já advertira, em A essência do cristianismo (1841), que

Pelo Deus conheces o homem e vice-versa, e pelo homem conheces o seu Deus; ambos são a mesma coisa. (...) Deus é a intimidade revelada, o pronunciamento do Eu do homem; a religião é uma revelação solene das preciosidades ocultas do homem, a confissão dos seus mais íntimos pensamentos, a manifestação pública dos seus segredos de amor. (FEUERBACH, 2007, p.44)

Mais tarde, em dezembro de 1843, Marx diria que, com Feuerbach, "a crítica da religião está, no essencial, terminada" (MARX, 2005, p.145). Como consequência da influência feuerbachiana, as questões mundanas não são mais transformadas em teológicas, como em Bauer. Ao contrário, as questões teológicas são transformadas 
em mundanas. Considerando essa nova abordagem, passa-se a compreender que "a miséria religiosa constitui ao mesmo tempo a expressão da miséria real e o protesto contra a miséria real" (MARX, 2005, p.145); que, sendo a religião a existência de uma carência, deve-se procurar sua fonte na essência do próprio Estado, o "sumário das lutas práticas da humanidade" (MARX, 2010, p.72); que a religião é apenas um fenômeno da limitação mundana, mas não a razão dela. Assim, o envolvimento religioso dos cidadãos livres passa a ser explicado a partir do seu envolvimento secular, ou seja, compreende-se que os cidadãos "suprimem sua limitação religiosa no momento em que suprimem suas barreiras seculares" (MARX, 2010, p.38), não que devam suprimir sua limitação religiosa antes das suas limitações seculares. Em resumo, nas palavras de György Lukács, "Marx mostra a posição que a religião em geral ocupa na sociedade burguesa e demonstra que a religião, seja judaica ou cristã, é o reflexo imaginário das relações sociais" (LUKÁCS, 2007, p.165).

É assim que "a questão da relação entre emancipação política e religião transforma-se na questão da relação entre emancipação política e emancipação humana" (MARX, 2010, p.38). Ao criticar o Estado político em sua construção secular, Marx critica os pressupostos gerais do Estado, inclusive sua debilidade religiosa: a contradição entre o Estado e uma religião particular transforma-se na contradição entre o Estado e a religião de modo geral. O Estado agora é visto como sujeito da emancipação, pois a emancipação política do homem religioso, de modo geral, consiste na emancipação do Estado em relação à religião. Assim, o Estado se emancipa da religião e se confessa Estado, de forma apropriada à sua essência: a universalidade, a abstração. Para Marx, a emancipação política em relação à religião não é a emancipação completa já efetuada, como seria a emancipação humana. Esta última, reivindicada por Marx, é aquela onde se realiza a absorção do cidadão abstrato pelo homem individual, que faz deste, em sua vida cotidiana, um ser genérico solidário com seus semelhantes. Segundo Lukács, trata-se de um novo ordenamento, que pressupõe "a negação da auto-alienação humana" (LUKÁCS, 2007, p.165). Em resumo, ela não mais separa o político e o não político.

Por sua vez, a emancipação política em relação à religião pode ser considerada parcial e insuficiente: ela não é completa. O Estado político é capaz de se libertar de uma limitação sem que o homem seja realmente livre, isto é, mesmo que a maioria dos cidadãos permaneça cumprindo deveres religiosos, o Estado é capaz de se emancipar da religião. Com isso, podemos constatar que o Estado político em si é pura abstração, isto é, esses cidadãos não deixam de ser religiosos, mesmo que no âmbito privado. Este é o limite da emancipação política, a separação entre o público e o privado, a libertação formal das limitações do homem. Acertadamente, em a Invenção Democrática (1983), no capítulo sobre os 
Direitos do homem e política, Claude Lefort define o conceito de emancipação política, dizendo que "Marx retém da revolução burguesa a delimitação de uma esfera da política como esfera do universal, à distância da sociedade, ficando esta reduzida, ao mesmo tempo, à combinação de interesses particulares e de existências individuais, decompostas em elementos" (LEFORT, 1983, p.45).

O que Marx trata de mostrar é a contraditoriedade interna da sociedade burguesa, marcada pela oposição entre essas esferas. O Estado, principalmente o Estado livre, comportase em relação à religião da mesma forma que as pessoas que compõe o Estado se comportam em relação à religião, ou seja, de modo religioso. Portanto, ao liberta-se politicamente através de um meio chamado Estado, o homem admite uma contradição consigo mesmo, permanecendo apenas parcialmente livre em relação à emancipação prática.

O problema de o homem libertar-se por intermédio do Estado é que mesmo o Estado se declarando ateu, o homem continua religiosamente condicionado, pois ele passa a reconhecerse de modo indireto, em um outro. Marx afirma que "a religião é justamente o conhecimento do homem mediante um desvio, através de um mediador", pois "Cristo é o mediador sobre o qual o homem descarrega toda a sua divindade, todo o seu envolvimento religioso" (MARX, 2010, p.39). Do mesmo modo, o "Estado é o mediador entre o homem e a liberdade do homem", pois ele "é o mediador para o qual o homem transfere toda a sua impiedade, toda a sua desenvoltura humana" (MARX, 2010, p.39). Assim, com o Estado sendo a barreira entre o homem e a liberdade do homem, Marx elabora a denúncia da alienação política. $\mathrm{O}$ homem se mantém alienado em sua realidade cotidiana porque no momento em que se coloca livre por meio do Estado político, da esfera política constituída como mero formalismo público, transcende a liberdade para uma esfera separada da sua vida material. Segundo Celso Frederico, em O jovem Marx, 1843 - 1844: As origens da ontologia do ser social (2009),

\footnotetext{
A interpretação feuerbachiana da religião é mantida integralmente por Marx: na figura de Cristo o indivíduo objetiva a sua humanidade e, graças a essa intermediação, pode reconhecer o seu ser genérico alienado. O mesmo vale para o Estado, o intermediário através do qual os indivíduos vislumbram a sua própria liberdade, as possibilidades infinitas do seu ser genérico. (FREDERICO, 2009, p.98)
}

Para Marx, essa elevação política do homem acima da religião "compartilha de todos os defeitos e de todas as vantagens de qualquer elevação política" (MARX, 2010, p.39). Nesse sentido, a propriedade privada, por exemplo, não só não é abolida com o fim do caráter censitário da elegibilidade, mas pressuposta, pois o legislador do não 
proprietário é justamente o proprietário. Ora, quando alguns estados norte-americanos aboliram o voto censitário, anularam, com isso, as distinções de renda. Acaso essas distinções acabaram? Ao proclamar a igualdade a cada membro do povo, então, o Estado anula à sua maneira todo tipo de diferenciação, seja de formação, estamento ou nascimento, considerando-as como diferenças apolíticas e tratando-as apenas como elementos da vida real de um povo, a partir do ponto de vista do Estado. O Estado permite que essas diferenças fáticas, como a propriedade privada e a atividade laboral, atuem à maneira delas e tornem sua essência particular viva e atuante. Com isso, a existência e a universalidade do Estado só se tornam ativas e efetivas opondo-se aos elementos que lhe são próprios. Ele se constitui como universal pelas vias particulares, justamente porque não se assume apenas um princípio particular, mas se obtém a "universalidade da ideia”, o princípio de sua forma, opondo-se em relação às particularidades. A referência é o parágrafo $\$ 270$ dos Princípios da filosofia do direito (1820), onde Hegel acertadamente determina a relação entre o Estado político e a religião.

Para que o Estado, como realidade moral do Espírito, consciente de si chegue à existência, é necessário que se diferencie da forma da autoridade e da crença. Ora, essa diferenciação só se realizará se no domínio religioso se der uma intrínseca separação. Só então o Estado atinge a universalidade do pensamento, que é o seu princípio formal, e o realiza acima das igrejas particulares. (HEGEL, 1997, p.243)

A oposição consumada na Revolução Francesa entre o Estado e a sociedade civil é essencial para o jovem Marx, pois é a partir dela que é possível compreender que "o Estado político pleno constitui, por sua essência, a vida do gênero humano em oposição à sua vida material" (MARX, 2010, p.40). O Estado representa o homem universal, porém seus pressupostos particulares continuam subsistindo na sociedade burguesa, como suas qualidades. É próprio da essência do Estado, em sua forma definitiva, que o homem viva uma vida dupla, tanto mentalmente, na consciência, como em sua realidade empírica: uma celestial e outra terrena, mas também uma comunitária e outra particular. $\mathrm{Na}$ comunidade política, considerando-se um ente comunitário (Gemeinwesen), e tal é a importância da emancipação política (apesar disso, o homem vive sua condição de ente comunitário de forma ilusória, justamente porque acredita que como ente abstrato as formalidades são suficientes para sua realização como sujeito não alienado), e na sociedade burguesa, considerando-se um ente particular, que vê nas pessoas o meio para conquistar, adquirir e acumular o que lhe interessa, "degradando-se a si próprio à condição de meio e sendo vulnerável a poderes externos e estranhos a ele" (MARX, 2010, p.40). 
Esta relação entre essas esferas é considerada espiritualista por Marx, tanto como a relação entre o céu e a terra, precisamente por conta da oposição entre tais esferas. A superação dessa antítese é o Estado político sendo obrigado a reconhecer a sociedade burguesa, deixandose dominar por ela, assim como a religião supera a limitação do mundo profano. Nesta situação, em sua realidade imediata na sociedade burguesa, o homem é considerado um ente estranho, um fenômeno inverídico, um sujeito ausente; no Estado, ele equivale a um ente abstrato, não constituído, nas palavras de Marx, "membro imaginário de uma soberania fictícia, tendo sido privado de sua vida individual real e preenchido com uma universalidade irreal" (MARX, 2010, p.41).

O conflito entre o homem que confessa uma religião particular e sua cidadania, entre ele e os demais homens que compõe a sociedade, se reduz na divisão secular universal entre o Estado político e a sociedade civil, isto é, o homem como judeu, citoyen, só permanece no Estado, na vida Estatal, mediante um sofisma, pois não abandona sua condição religiosa. Da mesma forma, o homem como membro da sociedade burguesa, bourgeois, tem no Estado apenas uma vida abstrata e irreal. Portanto, a relação contraditória entre o homem religioso e o cidadão é a mesma entre o cidadão e os pressupostos do Estado, ou seja, entre o proprietário de terras e o cidadão, entre o mercador e o cidadão, entre o diarista e o cidadão. Em resumo, a contradição que se coloca entre o homem religioso e o político é a mesma entre a sociedade burguesa e o Estado político, quer se tratem de elementos espirituais, como a religião, quer se trate de elementos materiais, como a propriedade privada. Em outras palavras, essa é uma contradição entre o interesse particular e o interesse geral, relação que, segundo Marx, Hegel buscou harmonizar mistificando.

\footnotetext{
A supressão da burocracia só pode se dar contanto que o interesse universal se torne realmente - e não, como em Hegel, apenas no pensamento, na abstração - interesse particular, o que é possível apenas contanto que o interesse particular se torne realmente universal. Hegel parte de uma oposição irreal e a conduz somente a uma identidade imaginária, ela mesma, em verdade, uma identidade contraditória. Uma tal identidade é a burocracia. (MARX, 2005, p.67)
}

Apesar disso, Bauer mantém todos esses antagonismos em seu texto, reconhece o Estado político como necessário e, por consequência, também a sociedade burguesa. Ora, o limite desse ordenamento é justamente a capacidade do homem de se emancipar politicamente da religião, banindo-a do direito público para o privado. Portanto, na emancipação política a religião passa a ser espírito da sociedade burguesa, não mais do Estado; ela se desloca 
para a esfera do egoísmo, como essência da diferença, não mais da comunidade. Nas palavras de Marx, "A interminável fragmentação da religião, por exemplo, na América do Norte, confere-lhe já exteriormente a forma de uma questão puramente individual" (MARX, 2010, p.42). A religião torna-se expressão da separação entre o homem e sua comunidade, entre o homem e os demais homens. Essa cisão do homem em cidadão e indivíduo, para Marx, "não constitui um estágio, e sim a realização plena da emancipação política" que, portanto, "não anula nem busca anular a religiosidade real do homem" (MARX, 2010, p.42).

Podemos, então, apoiando-se nesse quadro teórico, destacar a insuficiência da emancipação política em relação a emancipação humana, a emancipação prática. Marx faz questão de destacar isso: "estamos falando aqui de emancipação real, de emancipação prática" (MARX, 2010, p.41). Esse modo de se emancipar, o da emancipação política, permite que a religião perdure, independentemente de ser uma religião privilegiada, ou seja, ao contrário do que presume o Estado, a razão não é realidade em toda parte. Em resumo, de acordo com István Mészáros,

Marx compreende claramente que a superação prática da religião é inconcebível em termos exclusivamente políticos, tendo em vista o fato de que a política é apenas um aspecto parcial da totalidade dos processos sociais, por mais importante que possa ser em situações históricas específicas (por exemplo, na França em fins do século XVIII). (MÉSZÁROS, 2006, p.75)

Mas a oposição entre parcialidade da emancipação política e universalidade da emancipação humana tem um limite importante, limite que vale destacar. Segundo Mészáros, essa oposição "é concebida em sua generalidade bastante abstrata, e apenas um de seus aspectos é concretizado, negativamente, na rejeição de Marx da 'parcialidade política' como possível candidata a realizar a superação da alienação" (MÉSZÁROS, 2006, p.75). Desse modo, a contrapartida positiva dessa "parcialidade política" permanece obscura: a "universalidade" será identificada com a esfera ontologicamente fundamental da economia posteriormente no pensamento de Marx. O mesmo nos lembra Celso Frederico: “o desconhecimento da economia política havia deixado Marx numa visível situação de desvantagem quando de suas críticas à filosofia do direito de Hegel” (FREDERICO, 2009, p.94). Portanto, o tema da emancipação humana será discutido por nós com mais profundidade em outro momento, considerando os Manuscritos, de 1844, e a Ideologia alemã, de 1845.

\section{CONSIDERAÇÕES FINAIS}


Constatamos que a dissociação do homem em judeu e cidadão, em protestante e cidadão, em homem religioso e cidadão é a própria emancipação política, é o modo político de se emancipar da religião. Nesse sentido, em relação à religião, esse modo de se emancipar permite que a religião perdure, ainda que não se trate de uma religião privilegiada. Por um lado, o Estado político é capaz de se libertar de uma limitação sem que o homem seja realmente livre, isto é, mesmo que a maioria dos cidadãos permaneça cumprindo deveres religiosos, o Estado é capaz de se emancipar da religião. Por outro, ao liberta-se politicamente através de um meio chamado Estado, o homem admite uma contradição consigo mesmo, permanecendo apenas parcialmente livre em relação a emancipação prática. O problema de o homem libertar-se por intermédio do Estado é que mesmo o Estado se declarando ateu, o homem continua religiosamente condicionado, pois ele passa a reconhecer-se de modo indireto, em um outro. O homem transcende a sua liberdade para uma esfera separada da sua vida cotidiana, aparece a alienação política do homem. Nesse sentido, a essência mesma da emancipação política, não é necessário superar a religião para reivindicar um Estado democrático-burguês, como pensa Bauer, prova disso é que nos droits du citoyen e nos direitos humanos em geral a superação "positiva e irrefutável" da religião não está pressuposta. Por conta disso, Marx afirma que o homem não foi libertado da religião, mas ganhou a liberdade de religião; não foi libertado da propriedade, mas ganhou a liberdade de propriedade e etc. Estes limites expressam a contradição que caracteriza essa categoria, categoria que é apenas uma parte daquela oposição irreconciliável cristalizada na revolução francesa, entre o Estado político e a sociedade civil. 


\section{REFERÊNCIAS}

ENGELS, Friedrich. Anti-Dühring. Editora Paz e Terra, 1979.

FAUSTO, Ruy. Marx: Lógica e Política Investigações para uma reconstituição do sentido da dialética. Tomo I. Editora Brasiliense: São Paulo, 2015.

FURET, François. Marx e a revolução francesa. Editora Jorge Zahar: São Paulo, 1986.

FREDERICO, Celso. O jovem Marx. 1843 - 1844: As origens da ontologia do ser social. Expressão Popular: São Paulo, 2009.

HEGEL, Georg. Princípios da filosofia do direito. Editora Vozes: São Paulo, 1997.

HOBSBAWM, Eric. A era das revoluções (1789-1848). Editora Paz e Terra, 1962.

LEFORT, Claude. A invenção democrática: os limites da dominação totalitária. Editora Brasiliense: São Paulo, 1983.

LUKÁCS, György. O jovem Marx e outros escritos de filosofia. Editora UFRJ: Rio de Janeiro, 2009.

MARX, Karl. Crítica da filosofia do direito de Hegel. Boitempo Editorial: São Paulo, 2005, 2010. . Sobre a questão judaica. Boitempo Editorial: São Paulo, 2010.

MÉSZÁROS, István. A teoria da alienação em Marx. Boitempo Editorial: São Paulo, 2016. 